\title{
A MÚSICA E A SALA DE AULA INVERTIDA NO ENSINO À DISTÂNCIA
}

\author{
Roselaine Andrade Tavares ${ }^{1}$ \\ Gabriela de Vasconcelos Sousa ${ }^{2}$ \\ Frederico de Andrade Gabrich ${ }^{3}$
}

RESUMO: A partir do método científico hipotético-dedutivo, do referencial teórico estabelecido na Resolução n. 5 de 2018 do MEC, bem como pelas obras de Mônica Sette Lopes, de Jonathan Bergmann e Aaron Sams, esta pesquisa visa demonstrar que é possível um ensino jurídico a distância, que seja inovador e transdisciplinar, por meio da associação da música com a sala de aula invertida. Tudo isso com a participação ativa dos alunos.

PALAVRAS-CHAVE: Música; Sala de Aula Invertida; Ensino Jurídico; Ensino a distância; Metodologias ativas.

\section{MUSIC AND FLIPPED CLASSROOM IN DISTANCE LEARNING}

ABSTRACT: From the hypothetical-deductive scientific method, from the theoretical framework established in Resolution no. 5 of 2018 from MEC, as well as the works of Mônica Sette Lopes, Jonathan Bergmann and Aaron Sams, this research aims to demonstrate that it is possible to have a distance legal education, which is innovative and transdisciplinary, through the association of music with the room inverted class. All of this with the active participation of students

KEYWORDS: Music; Flipped Classroom; Legal Education; Distance learning; Active methodologies.

\section{INTRODUÇÃO}

O século XXI mal começou e já pode ser considerado como o tempo da consolidação e da expansão da globalização, bem como da verdadeira invasão da tecnologia na vida cotidiana da maioria das pessoas, o que será mais evidente ainda a partir do momento que se estabelecerem de fato as redes $5 \mathrm{G}$ e a internet das coisas. Desde o século anterior a ciência evoluiu muito e estabeleceu as bases necessárias para a realidade atual, especialmente em relação à revolução tecnológica determinada pela internet. Mas a imposição de toda essa

\footnotetext{
${ }^{1}$ Servidora do TJMG e Mestranda pela Universidade FUMEC

${ }^{2}$ Advogada e Mestranda pela Universidade FUMEC

${ }^{3}$ Doutor, Mestre e Especialista em Direito Comercial/Empresarial pela UFMG. Professor Adjunto da Universidade FUMEC
} 
evolução na educação se tornou realmente evidente a partir de março de 2020, quando foi declarada a pandemia da Covid-19 pela Organização Mundial da Saúde e quando as escolas e universidades tiveram de estabelecer, rapidamente, novas bases para o ensino e para a aprendizagem a distância.

Especificamente no ensino jurídico, em um ano letivo tomado pela incerteza, alunos e professores foram obrigados a manter o distanciamento social e a dar início a uma nova era do ensino do Direito. Docentes, que antes estavam plenamente adaptados (e, em alguns casos, até acomodados) ao modelo tradicional das aulas presenciais, viram-se de repente em salas de aula virtuais, com aulas transmitidas ao vivo de dentro de suas casas, sendo "forçados" a repensar toda a dinâmica de ensino, de aprendizagem e de relacionamento com os seus alunos, muitas vezes sem qualquer estudo, treinamento ou preparação minimamente necessária para isso.

No entanto, a tarefa também é árdua porque os antigos problemas que podiam ser verificados nas aulas presenciais no momento anterior à pandemia, continuam no novo ensino a distância, marcado pelas aulas síncronas. A falta de motivação e de participação dos alunos, agora, ficam evidentes pela participação cada vez mais passiva dos estudantes, que nem mesmo ativam os comandos de áudio e de vídeo dos seus computadores e/ou smartphones durante as aulas. Além disso, a mesma insegurança e sobrecarga de atividades que atinge os professores, também é realidade dos alunos e não pode ser desconsiderada nesse contexto.

Mas essa é a realidade e este é o problema que esta pesquisa procura enfrentar: o ensino jurídico precisa evoluir e se adaptar rapidamente à nova situação, e os professores de Direito precisam ter acesso a metodologias e métodos que possam ser usados virtualmente e que também garantam maior participação, engajamento e aprendizagem por parte dos alunos. Mais do que nunca, é preciso discutir métodos ativos e mais inovadores de ensino, que permitam a customização, a personalização e a efetiva participação dos alunos. O desafio é maior considerando a incerteza acerca do futuro, a ansiedade e todos os males advindos do isolamento social decorrente da pandemia.

Uma alternativa para todas essas necessidades é o uso da sala de aula invertida como método ativo de ensino a distância, aliado ao uso da música.

Como se sabe, o Direito é uma ciência social aplicada e, por isso, passível de ser associada às mais diversas manifestações humanas, bem como com acontecimentos e contextos socioeconômicos e culturais, muitos deles reconhecidos (explícita ou 
implicitamente) pelas normas jurídicas, estabelecidas no ordenamento pelas mais diversas fontes (lei, costumes, jurisprudência, atos administrativos, contratos etc.). O ensino jurídico, presencial ou a distância, precisa reconhecer essa realidade e ser realizado de forma inter, multi e transdisciplinar.

A Resolução no 5 do Ministério da Educação, de 17/12/2018, corrobora com esse entendimento ao estabelecer que o Projeto Pedagógico do Curso de Direito (PPC), deve ter como elementos estruturais, dentre outros, a realização da transdisciplinaridade, do incentivo à inovação, da integração entre teoria e prática, bem como a especificação das metodologias e métodos ativos utilizados.

Nesse sentido, visando um ensino mais inovador, transdisciplinar e significativo para todas as partes envolvidas no processo educacional (especialmente alunos e professores), os diálogos possíveis entre o Direito e a arte podem ser explorados em diversos níveis. Especificamente nesta pesquisa, optou-se por associar a música à sala de aula invertida visando uma maior interação, participação e aprendizado no ambiente virtual de ensino, comum em tempos de pandemia.

Assim, a partir do método científico hipotético-dedutivo, do referencial teórico estabelecido na Resolução n. 5 de 2018 do MEC, bem como pelas ideias de Mônica Sette Lopes, na obra denominada "Uma metáfora: Música e Direito", assim como pelas propostas de Jonathan Bergmann e Aaron Sams, no livro "Sala de aula invertida: Uma metodologia ativa de aprendizagem", esta pesquisa visa demonstrar que é possível o ensino jurídico a distância ser inovador e transdisciplinar, por meio da associação da música com a sala de aula invertida.

O tema é apresentado e contextualizado nesta pesquisa, de modo a demonstrar que o uso de metodologias ativas, conectando a música com a sala de aula invertida, aplicadas ao ensino do Direito a distância, pode proporcionar não apenas um ensino/aprendizagem eficiente, ativo e transdisciplinar, mas também uma melhor capacidade de compreensão, argumentação, comunicação e de persuasão dos profissionais e operadores do Direito.

\section{A MODERNIZAÇÃO DO CONCEITO DE EDUCAÇÃO}


O primeiro capítulo do presente artigo científico visa analisar a evolução do ensino jurídico no tempo, partindo-se da estrutura pedagógica utilizada no modelo instrutivista de ensino, que evoluiu com o surgimento de métodos que inovaram o paradigma tradicional de educação.

\subsection{Reflexões acerca da aplicação do método instrutivista no ensino jurídico}

Considerando o ensino de todas as ciências, além do ensino jurídico, o processo de aprendizagem ocorre tradicionalmente por meio do modelo instrutivista de ensino, em que o professor exerce o papel de sujeito ativo e o aluno de sujeito passivo no ambiente de sala de aula. Por meio desse modelo, o conteúdo é ministrado pelo docente por meio de aulas expositivas, em que ele exerce a figura de único responsável pelo processo de cognição da turma, sendo a participação dos alunos limitada a de espectadores (FREITAS, 2012, p. 412 413).

Sobre essa modalidade de ensino mecanizado, que perdura durante séculos, Jonathan Bergmann e Aaron Sams (2016, p.10) alegam o seguinte:

\footnotetext{
“Os alunos são educados em linha de montagem, para tornar eficiente a educação padronizada. Sentam-se em fileiras de carteiras bem arrumadas, devem ouvir um "especialista" na exposição de um tema e ainda precisam se lembrar das informações recebidas em um teste avaliativo. De alguma maneira, nesse ambiente, todos os alunos devem receber uma mesma educação. A debilidade do método tradicional é a de que nem todos os alunos chegam à sala de aula preparados para aprender. Alguns carecem de formação adequada quanto ao material, não têm interesse pelo assunto ou simplesmente não se sentem motivados pelo atual modelo educacional".
}

Além disso, sobre esse modelo educacional tradicional de ensino oferecido pelas instituições que ministram o curso de Direito, Temer Fakhoury Filho e Frederico de Andrade Gabrich observam o seguinte:

\footnotetext{
“(...) a educação jurídica tem acontecido tradicionalmente por meio da utilização de um modelo pedagógico essencialmente instrucionista, conteudista, conceitualista, focado no professor. Calcado principalmente na metodologia das aulas expositivas, utiliza uma abordagem exageradamente dogmática e estática, que acaba por mitigar o verdadeiro potencial da educação andragógica, crítico-reflexiva e transformadora (...)" (FAKHOURY FILHO; GABRICH, 2016, p.10).
}

Esse modelo instrutivista, apesar de ser ainda muito utilizado e responsável por parte significativa de todo o conhecimento produzido até o século XXI, como estratégia de ensino já pode ser considerado ultrapassado, principalmente quando aplicado como única técnica pelo educador em suas aulas. De fato, o ensino exclusivamente instrutivista pouco estimula os 
alunos a desenvolverem o raciocínio crítico-reflexivo sobre os temas objeto de estudo, além de não ser capaz de aliar adequada e significativamente o conhecimento teórico ao conhecimento prático.

Certo é que com o passar dos anos e com o desenvolvimento do estudo científico sobre a educação, pesquisadores de todo o mundo desenvolveram uma série de métodos de ensino que atendem melhor às necessidades atuais dos alunos, que devem ser observados enquanto sujeitos individuais e com necessidades específicas, em um mundo realmente marcado por problemas complexos, globais e intergeracionais.

\subsection{A expansão dos cursos de Direito no Brasil}

A importância da evolução técnica e temporal dos projetos pedagógicos de ensino, que pode ocorrer por meio do uso metodologias construtivistas e construcionistas, bem como por intermédio de métodos ativos de ensino e aprendizagem, não se revela somente essencial para o avanço das instituições que oferecem cursos de Direito, mas sim para os acadêmicos que ali realizam e concluem os seus cursos, pois eles precisam sair preparados para enfrentar os dilemas cotidianos da sociedade, que carece de profissionais realmente qualificados para o enfrentamento dos problemas atuais (RIGHETTI, 2008).

No ensino jurídico no Brasil, ocorreu uma expansão desenfreada de oferta de cursos de Direito, enquanto pouco se focou na qualidade e no nível do projeto pedagógico apresentado pelas instituições de ensino. Esse fato se deu tendo em vista que o Ministério da Educação reconheceu esses cursos no mercado, sendo que os números já excedem à 1.000 (um mil) instituições autorizadas a funcionar e credenciadas pelo MEC (FOREQUE, 2013, p. 1).

Consequência direta dessa expansão é que muitos dos bacharéis em Direito saem das universidades com a impressão de que nada aprenderam, não sendo capazes sequer de passar no temido Exame da Ordem, requisito para a atuação no ramo da advocacia e primeiro desafio a ser enfrentado pelos profissionais da área jurídica.

Fato que comprova isso é que no ano de 2017 ocorreu um recorde de reprovação em uma das provas anuais oferecidas pela Ordem dos Advogados do Brasil, oportunidade em que 
somente $14,98 \%$ dos candidatos foram aprovados na primeira fase do certame (MARTINES, 2017).

Além disso, o número de alunos que efetuam a matrícula no curso de Direito, em contraponto com a quantidade de concluintes, é geralmente gritante em parte significativa das instituições. ${ }^{4}$ Existe o estímulo para iniciar o curso, em busca de boa colocação no mercado de trabalho, porém, falta o estímulo para concluir. E, muito provavelmente, essa falta de estímulo e de interesse decorra da ausência mais significativa do uso de metodologias construtivistas e construcionistas no ensino jurídico, aliadas ao uso de métodos realmente ativos, que promovam a efetiva participação dos alunos no processo educacional.

\subsection{O uso de métodos ativos de ensino como forma estratégica e construtivista de desenvolvimento do aprendizado}

Na concepção de Hamilton Werneck “(...) o saber é importante na medida em que o ser humano é capaz de comunicá-lo aos seus semelhantes e colaborar para a mudança do meio em que vive (...) (WERNECK, 2012)”. A partir dessa premissa, é fato que a arte de ensinar exige uma comunicação adequada, além da necessidade da ruptura de antigos paradigmas, que já não são adequados para contribuir com a formação de indivíduos enquanto profissionais capacitados para atuar na sociedade.

O ensino tradicional, marcadamente instrutivista, embora continue sendo importante, não atende mais exclusivamente às necessidades e anseios dos alunos, que estão cada vez mais imersos em uma sociedade pautada por problemas realmente complexos. Existe a necessidade de reavaliar as metodologias e métodos de ensino-aprendizagem usados no ensino jurídico no Brasil, principalmente diante de um contexto em que os alunos se formam geralmente sabendo muito pouco para atuarem na prestação de serviços jurídicos (o que pode ser comprovado pelos baixos índices de aprovação nos exames de qualificação profissional oferecidos pela Ordem dos Advogados do Brasil, ou mesmo nos concursos públicos exclusivos para a área jurídica).

\footnotetext{
${ }^{4}$ BRASIL, Educa mais. Jornal Estado de Minas. Disponível em: https://www.em.com.br/app/noticia/especiais/educacao/2018/07/17/internas educacao,973969/indice-detroca-ou-abandono-de-curso-em-faculdades-equivale-a-metade-d.shtml. Acesso em: 15 set. 2020.
} 
A realidade mostra que boa parte dos professores não se utiliza das novas técnicas de ensino capazes de prender a atenção e de conectar os alunos, de promover o raciocínio críticoreflexivo, de prepará-los para a solução de problemas complexos e intergeracionais. Além disso, poucos professores realmente planejam as suas aulas para a superação dessas necessidades dos alunos, ou mesmo para criar um ambiente mais propício à aprendizagem que tenha valor para os discentes (FAKHOURY FILHO, GABRICH, 2016).

De fato, os professores de Direito precisam saber que o trabalho deles vai muito além de exigir a memorização de textos legais para a realização de provas mal formuladas. Os estudantes de Direito precisam atualmente ser preparados por seus professores para a estruturação eficiente dos objetivos das pessoas (naturais e jurídicas), sem que tal organização jurídica de objetivos determine o surgimento de conflitos ou que estes sejam solucionados por meio de processos judiciais. Os estudantes também precisam ser preparados para saber ouvir, contextualizar, negociar, mediar, solucionar problemas complexos (na esfera judicial e extrajudicial), bem como combinar conhecimentos jurídicos com outros estudados em outras ciências, em um mundo cada vez mais dinâmico e plural.

Necessário então abandonar a ideia instrutivista de ensino e partir para o conhecimento construtivista, em que o ambiente de ensino deve abranger técnicas que estimulem a construção do conhecimento a longo prazo. Nesse sentido:

\footnotetext{
“O construtivismo propõe que o aluno participe ativamente do próprio aprendizado, mediante a experimentação, a pesquisa em grupo, o estímulo a dúvida e o desenvolvimento do raciocínio, entre outros procedimentos. A partir de sua ação, vai estabelecendo as propriedades dos objetos e construindo as características do mundo. (NIEMANN; BRANDOLI, 2012).
}

Posto isso, métodos ativos de ensino devem ser implementados, com o objetivo de estimular os alunos ao desenvolvimento do conhecimento crítico, além de aliar o conhecimento técnico à realidade.

Um desses métodos que funciona e incentiva a participação ativa dos alunos no ambiente de sala de aula é a sala de aula invertida que, para maior eficiência e estímulo ao ensino contemporâneo, pode ser aliado ao uso da música.

\section{A SAlA DE AULA INVERTIDA E A MÚSiCA COMO MÉtodos ATIVOS DE ENSINO}


No presente capítulo será abordada a sala de aula invertida, associada ao uso da música enquanto método ativo de ensino personalizado, apresentando-se a sua lógica, a forma de aplicação e os benefícios provenientes do seu uso no ensino jurídico.

\subsection{Abordagem inicial}

Com a expansão da globalização e da informática, considera-se que a maior parte dos alunos já possui acesso à tecnologia por meio de algum instrumento digital, sendo que grande parte das instituições de ensino já tenta aliar esses novos mecanismos informatizados com a educação (MOURA; TASSIGNY; SILVA, 2018, p.9).

Quando o objetivo educacional é pautado na proatividade dos alunos nas aulas, é primordial que sejam desenvolvidas tanto atividades consideradas simples, quanto as mais complexas, com o objetivo de estimular os educandos a aplicarem o conhecimento teórico adquirido em situações praticas, o que deve ocorrer por meio da sua criatividade e livre iniciativa. Para tanto, devem ser adotadas metodologias e métodos de ensino que incentivam esse desenvolvimento do conhecimento mais profundo, que será aproveitado por longo prazo (MORAN, 2017, p. 8).

A partir disso, foi criada a ideia da sala de aula invertida, ou "flipped classroom", que embora tenha sido pesquisada desde os anos 90, foi efetivamente implantada por Jonathan Bergman e Aaron Sams no ano de 2006, conforme demonstrado na obra "Sala de Aula Invertida: Uma Metodologia Ativa de Aprendizagem", cujas ideias representem o principal marco teórico do presente estudo.

A sala de aula invertida é um recurso pensado para otimizar o aprendizado no século XXI, pois considera que todos os alunos são seres com realidades, habilidades e necessidades distintas, sendo que, além da falta de interesse manifestada por muitos, em muitos casos é preciso considerar também a sobrecarga de atividades extracurriculares e pessoais, que muitas vezes dificultam o processo de aprendizagem e o trabalho do professor.

Nessa modalidade de ensino, em momento anterior à aula, o aluno recebe do professor um módulo contendo vídeos, textos e tarefas sobre o conteúdo a ser ministrado, para que seja realizado um estudo prévio.

O tempo em sala de aula, em que a matéria seria tradicionalmente exposta pelo professor, transforma-se em um momento para debates, esclarecimento de dúvidas e realização de atividades práticas. 
A importância desse mecanismo se dá considerando que nesse modelo os alunos são compreendidos a partir das suas reais necessidades, sendo facultado a eles contemplar o seu próprio ritmo de estudo, além de serem atendidos pelo professor conforme as suas dificuldades individuais (IVAN et al, 2013; TOMELIN, 2014).

Ou seja, nesse modelo personalizado de ensino, os alunos são observados pelo educador a partir das suas diferentes motivações, expectativas e objetivos perante a vida, facilitando a descoberta dos aspectos mais relevantes a serem estimulados na turma, que pode acontecer por meio de atividades cooperativas e competitivas, a serem realizadas em grupo ou de forma individual (MORAN, 2017, p. 3).

A partir do uso da sala de aula invertida, o conhecimento se torna mais amplo do que seria no ambiente tradicional de ensino, no qual os alunos exerceriam um papel passivo na classe. Tal conhecimento é efetivado por meio de uma construção da aprendizagem entre os alunos e o professor, com colaboração mútua, abordando as três fases principais da aprendizagem, notadamente a fase individual, a fase grupal e a fase orientada.

\subsection{O Direito e a música aliados no processo de aprendizagem}

A música detém diversos usos e finalidades na vida das pessoas, seja de modo a induzir a concentração, a exercitar-se fisicamente, a animar uma festa, até auxiliar na aprendizagem.

A proximidade entre música e Direito vem de muito tempo atrás, com finalidades estabelecidas ao longo dos tempos pela sociedade, tanto com relação à música, quanto com relação ao Direito, inclusive relacionando-os à fé e às religiões. Nesse sentido, Lopes afirma que "a música tem a capacidade de, nos rituais religiosos, expressar condutas a seguir, o ritmo, o como agir, tudo dentro daquela determinada comunidade, tornando-se a música um fator de sociabilidade e harmonia" (LOPES, 2006, p. 24).

Tanto na música quanto no Direito, o intérprete detém papel fundamental, uma vez que, geralmente, quem define a extensão e o alcance do conteúdo da partitura, da letra da canção, do texto da lei, não é a expressão formal, mas o trabalho objetivo e também subjetivo do intérprete ao realizar seu trabalho minuciosamente.

Segundo Eros Roberto Grau, ex-Ministro do Supremo, “os músicos interpretam partituras visando à fruição estética. Os juízes interpretam textos normativos vinculados pelo 
dever de aplicá-los, de sorte a proverem a realização de ordem, de segurança e de paz" (GRAU, 2014, p. 15).

Do mesmo modo, em relação a interpretação, Lopes esclareceu em uma entrevista ao programa Opinião Minas, da Rede Minas de Televisão, que o operador do Direito precisa saber "tocar" em diversas áreas do Direito, seja tributário, consumidor, civil, penal, adequando a metodologia e as formas de comunicação. Lopes lembrou que "não adianta ter técnica se não tiver sensibilidade" (LOPES, 2012).

Portanto, ao operador do Direito, é de extrema importância saber interpretar a letra da lei, o que pode ser feito em analogia com a música, pois, quem compreende o sentido de uma letra musical detém a habilidade necessária para também interpretar a lei.

Gabrich e Tavares ressaltam essa habilidade ao afirmarem que:

\begin{abstract}
Estudar e ensinar o Direito não pode se resumir apenas à técnica, à memorização dos textos das normas, ao conhecimento da doutrina, mas, assim como na música, é preciso ter sensibilidade para interpretar fatos, valores e normas, inseridas em um determinado contexto socioeconômico e cultural, que pode variar no tempo e no espaço (GABRICH, TAVARES, 2020, p. 45).
\end{abstract}

Deste modo, vários fatores devem ser observados ao se realizar uma interpretação, seja de leis, de contratos ou de textos jurídicos, pois, estes fatores podem induzir o intérprete ao erro, bem como levá-lo a diferentes conclusões a depender do momento, do tempo e do espaço.

Com base na obra de Lopes (2006), pode-se dizer que, além do perfil interpretativo, essa conexão entre o Direito e a música enseja dar aos operadores do Direito uma visão mais humanista dos fenômenos jurídicos, bem como uma nova maneira de pensar e de agir profissionalmente, pois, o Direito e a arte são manifestações comunicativas e racionais que se completam, especialmente na perspectiva do ensino, com importantes possibilidades de utilização prática, sobretudo no que diz respeito à argumentação e justificação jurídicas, que podem estar presentes nas monografias, nas petições, nas sentenças e na doutrina.

\title{
3.3 Atualização do ensino jurídico no Brasil e uso da música como método ativo
}

Ao se referir ao ensino do Direito no Brasil, é notório que ele tem passado por mudanças, as quais são necessárias e prementes quando se pretende acompanhar a evolução da sociedade e do modo de ensinar - especialmente o Direito. 
As bases estruturais dessas mudanças, podem ser observadas desde os comandos estabelecidos pela Lei de Diretrizes e Bases da Educação (LDB), Lei n ${ }^{\circ} 9.394$ de 20 de dezembro de 1996, segundo a qual:

\begin{abstract}
Art. 43. A educação superior tem por finalidade: I - estimular a criação cultural e o desenvolvimento do espírito científico e do pensamento reflexivo; II - formar diplomados nas diferentes áreas de conhecimento, aptos para a inserção em setores profissionais e para a participação no desenvolvimento da sociedade brasileira, e colaborar na sua formação contínua; III - incentivar o trabalho de pesquisa e investigação científica, visando o desenvolvimento da ciência e da tecnologia e da criação e difusão da cultura, e, desse modo, desenvolver o entendimento do homem e do meio em que vive; IV - promover a divulgação de conhecimentos culturais, científicos e técnicos que constituem patrimônio da humanidade e comunicar o saber através do ensino, de publicações ou de outras formas de comunicação; V suscitar o desejo permanente de aperfeiçoamento cultural e profissional e possibilitar a correspondente concretização, integrando os conhecimentos que vão sendo adquiridos numa estrutura intelectual sistematizadora do conhecimento de cada geração; VI - estimular o conhecimento dos problemas do mundo presente, em particular os nacionais e regionais, prestar serviços especializados à comunidade e estabelecer com esta uma relação de reciprocidade (BRASIL, 1996).
\end{abstract}

Assim, a LDB, ao elencar as finalidades da educação superior no Brasil, contribui e estipula os parâmetros para torná-la uma educação de qualidade e contextualizada com os principais problemas do mundo presente, em particular os nacionais e regionais.

A Resolução n. 5 do Ministério da Educação, de 17 de dezembro de 2018, também estabelece mudanças específicas no âmbito do curso de Direito, as quais buscam atualização, qualidade e contextualização tanto da grade curricular como do ensino em si, decorrentes inclusive da implementação das diretrizes curriculares estabelecidas pela referida Resolução, segundo a qual, o ensino jurídico precisa ser inovador, usar metodologias ativas, bem como ser inter, multi e transdisciplinar.

Esta Resolução estabelece em seu artigo $2^{\circ}$ que no Projeto Pedagógico do Curso (PPC), dentre outras, deverão constar: V - as formas de realização de interdisciplinaridade, de mobilidade nacional e internacional, de incentivo à inovação e de outras estratégias de internacionalização, quando pertinente; VI - os modos de integração entre teoria e prática, especificando as metodologias ativas utilizadas; bem como IX - o incentivo, de modo discriminado, à pesquisa e à extensão, como fator necessário ao prolongamento da atividade de ensino e como instrumento para a iniciação científica.

Portanto, com base nessas possibilidades e exigências, os cursos de Direito podem e devem se utilizar de métodos de ensino inovadores, transdisciplinares, que valorizem o 
ativismo discente, permitindo, inclusive, por exemplo, associar a música à sala de aula invertida, realizando conexões inter, multi e transdisciplinares num ambiente virtual e proporcionando mais interação entre os alunos.

Logo, pode-se dizer que ao se propagar o ensino do Direito a distância, em função da pandemia de Covid-19, acabou-se por proporcionar mais uma forma de modernizar o ensino jurídico, o qual vem sendo desenvolvido virtualmente, tanto no nível da graduação, quanto da pós-graduação.

Nesse sentido, preconiza Gabrich:

O ensino jurídico precisa evoluir para reconhecer a importância atual da transdisciplinaridade e a sua capacidade de restabelecer a força, a significação e o interesse do ensino do Direito, especialmente diante dos novos paradigmas da contemporaneidade e dos interesses das novas gerações de estudantes e de profissionais do Direito (GABRICH, 2013, p.16).

Portanto, é possível e necessário atualizar o modo de se ensinar o Direito, e uma opção ao alcance de todos é utilizar-se da música, pois, trata-se de um recurso amplamente acessível, seja por meio do rádio, da internet ou de aplicativos.

E a música, em conexão com o Direito, pode ainda aproximá-lo do cotidiano das pessoas, dos problemas do mundo presente, e contribuir para um ensino jurídico mais eficaz, inovador e transdisciplinar.

\section{ASSOCIAÇÃO DA MÚSICA À SALA DE AULA INVERTIDA COMO MÉTODO ATIVO TRANSDISCIPLINAR}

No presente capítulo, será demonstrado como o uso da música pode ser um aliado na aplicação da sala de aula invertida no ensino do Direito a distância.

\subsection{Direito, música e sala de aula invertida: uma associação transdisciplinar}

É fato que a sala de aula pode se tornar um ambiente de estudo transdisciplinar ao se utilizar da modalidade da "flipped classroom" associada à música em um ambiente virtual de ensino e de aprendizagem.

Nota-se que um dos grandes desafios no ensino do Direito contemporâneo é o abandono do modelo mental e da metodologia marcadamente instrutivista de ensino, ainda muito usada em diversas instituições de ensino e por muitos professores, como a principal 
(senão a única) metodologia. A dificuldade da superação desse problema passa por diversos fatores, como, por exemplo, a deficiência dos projetos pedagógicos reais dos cursos, a estrutura curricular rígida, o modelo mental instrutivista dos(as) coordenadores(as) de cursos e dos próprios alunos, a falta ou a deficiência da formação e da requalificação dos professores dos cursos jurídicos. Todavia, todas essas vicissitudes, problemas e percalços podem ser superados uma vez que as instituições de ensino, seus coordenadores e, sobretudo, os professores reconheçam e acolham a ideia de que o Direito é uma ciência social aplicada que se relaciona com outras disciplinas, com outras ciências, com os fatos sociais e culturais, com as artes e com aquilo que também não é considerado como ciência formal, possuindo com todos esses conhecimentos uma relação de proximidade e de interação, capaz de favorecer (e muito) a eficácia do processo de ensino e de aprendizagem. A partir disso, surge a ideia de um ensino jurídico transdisciplinar, que, conforme Gabrich, pode se traduzir em algo "fundamental para a adoção da análise holística, completa e total que caracteriza a transdisciplinaridade" (GABRICH, 2013, p.13).

A sala de aula invertida permite de fato um ensino transdisciplinar, eis que esse método pode ser aplicado e colocado virtualmente em prática pelo professor, e pode facilmente permitir a conexão dos temas jurídicos com outros objetos de conhecimento (científico ou não). Nesse sentido, ao associar a música a este modelo, quando por exemplo, no material enviado previamente aos alunos, além de textos e vídeos, inclui-se música ou letras de música nos módulos objeto de estudo, é possível proporcionar aos alunos a oportunidade de fazer associações transdisciplinares que os levem não apenas a conhecer mais profundamente o objeto de estudo jurídico, mas a promover o raciocínio crítico-reflexivo e contextualizado com problemas complexos de ordem ética, social, cultural, econômica, que interagem e modificam a interpretação e a aplicação das normas jurídicas aos casos concretos.

Com base no material disponibilizado previamente, o aluno pode realizar em casa um estudo prévio, interativo e transdisciplinar, e a partir daí podem ser despertadas inquietações, pensamentos e ideias distintas acerca do conteúdo que lhes foi enviado, tendo em vista o próprio contexto social e cultural no qual os alunos estão inseridos, o que lhes dá oportunidade de levar para a sala de aula, ainda que virtual, debates acerca dos mais variados assuntos, quando consideradas essas diversas realidades individuais que são vivenciadas no cotidiano e que também possuem conexão direta ou indireta com disciplinas, em princípio, fora do Direito.

Revista de Pesquisa e Educação Jurídica | e-ISSN: 2525-9636 | Encontro Virtual | v. 6 | n. 2 | p. 75 - 94 | Jul/Dez. 2020. 
Considerando que a virtualização da educação ocupou um papel de destaque no momento pandêmico atual, o que se estimula é a aplicação da música na sala de aula invertida, também neste formato de ensino virtual, visando uma aproximação com os alunos, além de um modo mais atrativo de ensino, cientes de que são necessárias adequações para garantir essa atenção, motivação e efetividade do aprendizado construído pelos alunos.

O modelo da sala de aula invertida, no presente caso, associado com a música, faculta ao estudante, além de escolher o melhor horário e o ambiente mais propício para a sua aprendizagem, a chance de também contribuir com o próprio aprendizado e com o dos colegas, de acordo com a sua vivência e particularidades, fazendo sugestões e observações tanto no estudo extraclasse quanto naquele realizado em turmas virtuais.

Aliado a esse fato, quando se trata do aprendizado a distância discorrem Karina e Janes Tomelin:

\footnotetext{
Uma das características comumente citadas quando se remete ao aprendizado na educação a distância é a de autonomia. O estudante tem autonomia para organizar seu tempo de estudo e assim escolher a melhor hora para aprender. Associado a autonomia, porém, está a disciplina, já que sem ela o aprendizado não é garantido. A autonomia no sentido empregado na educação a distância é que possibilita ao estudante o autogerenciamento da sua rotina acadêmica bem como da habilidade de escolha e organização (TOMELIN, 2015).
}

Aplicando-se a interação entre a música e sala de aula invertida no formato virtual, nas videoconferências que substituíram as aulas presenciais, os alunos podem ser estimulados a participarem mais das aulas e, quem sabe, com as câmeras ligadas, de modo a atuarem de forma mais ativa, em conjunto com o professor e com os outros alunos, que podem apresentar sua visão e compreensão daquilo que lhe foi enviado previamente, permitindo-lhes ainda trazer outras sugestões de músicas, ritmos e estilos musicais que também mencionem aquele tema/assunto que está em pauta na aula do dia.

Assim, as atividades de fixação a serem aplicadas na sala de aula podem de fato prender mais a atenção do aluno, de forma que ele se dedique completamente ao estudo naquele determinado momento do dia. E a música pode contribuir com essa necessária atenção uma vez que se trata de uma manifestação artística altamente democrática. Enfim, é um trabalho que demanda criatividade por parte do educador, exigindo experiência e técnica, mas que também pode garantir uma participação ativa e significativa dos alunos, para a superação dos problemas identificados antes nesta pesquisa. 
No entanto, os benefícios advindos do uso da "flipped classroom musical", neste ambiente online tem impacto direto na ampliação do desenvolvimento do aprendizado transdisciplinar, inclusive a longo prazo, tornando a sala de aula um ambiente propício ao debate e a absorção de novos conhecimentos que serão compartilhados e não somente como uma obrigação monótona, onde os educandos são compelidos a estar presentes em uma vídeoconferencia em um determinado momento do dia.

Como exemplos práticos ${ }^{5}$ de aplicação da música ao ensino do Direito, utilizáveis também na sala de aula invertida, pode-se mencionar as sugestões trazidas por GABRICHH e TAVARES (2020) quando afirmam que se pode com a música estudar, por exemplo, o Direito Autoral (Lei n 9.610/1998), ao se discutir de quem são os direitos autorais de determinada música, analisando se foi plagiada, traduzida, ou editada, fazendo ponte, inclusive, com o art. 184 do Código Penal Brasileiro (Decreto-Lei no 2.848, de 7/12/1940), que define que "violar direitos do autor e os que lhe são conexos, é crime punido com pena de detenção de três meses a um ano, ou multa" (BRASIL, 1940).

Os mesmos autores afirmam, ainda, que as tradicionais marchinhas de carnaval, sob a luz da atual legislação em vigor, poderiam expressar uma lista de possíveis crimes como, por exemplo racismo, homofobia e bullying, contidos ou incitados em letras com trechos infelizes, redigidos em outras épocas e que hoje agridem direitos legalmente protegidos. Em trechos como "nega do cabelo duro", "Maria sapatão", "Olha a cabeleira do Zezé/ será que ele é?" nota-se ofensas ao tipo de cabelo, de opção sexual, de cor, de raça, o que hoje não se admite no ordenamento jurídico nacional.

É importante ressaltar, portanto, que ao se utilizar da música no ensino transdisciplinar do Direito, associando-a à sala de aula invertida, existem diversas possibilidades de participação e de interação, que podem, de fato, promover um ensino inovador, atual, inter, multi e transdisciplinar, capaz de promover a conexão entre teoria e prática, além da formação de alunos preparados para a solução de problemas complexos e intergeracionais. Tudo conforme estabelecido pela LDB e pela Resolução n. 5/2018 do MEC.

\section{CONSIDERAÇÕES FINAIS}

\footnotetext{
5 Artigo “Aplicação da música ao ensino do Direito" disponível em https://indexlaw.org/index.php/rpej/article/view/6519/pdf.
} 
Considerando os pontos abordados no presente trabalho, conclui-se, em primeiro lugar, que o uso da modalidade de ensino a distância nos cursos de Direito é uma realidade que, muito provavelmente, irá se manter de alguma forma no ambiente pós- pandemia.

De qualquer maneira, no ensino presencial ou no ensino a distância, antes ou depois da pandemia, será necessário estabelecer e aperfeiçoar um ensino do Direito que seja inovador, inter, multi e transdisciplinar, mas também que garanta um maior nível de participação dos alunos.

Nesse contexto, a expansão do EAD e consequente modernização do ensino jurídico constituem grandes desafios a serem enfrentados no que concerne a construção e a adequação do conhecimento à realidade atual. E esse é um problema que precisa ser enfrentando não apenas pelas instituições de ensino, mas também pelos professores e alunos dos cursos jurídicos.

Isso ocorre porque, conforme explicitado no presente artigo, existe uma dificuldade real dos professores para estimularem os alunos a participarem efetivamente do ambiente virtual de aprendizagem. Além disso, há grande dificuldade de atingir os objetivos estabelecidos pela legislação atual, com destaque para a Resolução n. 5/2018 do MEC, nos projetos e nas práticas pedagógicas dos cursos jurídicos.

No entanto, essa realidade pode ser transformada por meio do uso de metodologias construtivistas e construcionistas, bem como por intermédio de métodos ativos de ensino, como ocorre com o uso da sala de aula invertida associada à música, quando o aluno realiza a construção do conhecimento em conjunto com o professor. Por esse caminho, como restou demonstrado, os acadêmicos são estimulados a participar construtivamente antes e durante o momento da aula, bem como a promover o raciocínio crítico-reflexivo, a comunhão entre a teoria e a prática, a interpretação contemporânea dos fatos jurídicos etc.

Além disso, os alunos que possuem mais interesse no tema a ser ministrado, têm a oportunidade de aprofundar os conhecimentos para posteriormente discutir com o professor, gerando uma abertura a debates construtivos e transdisciplinares, o que acaba colaborando para o aprendizado de toda a turma.

A participação ativa nas aulas e esse desenvolvimento do conhecimento prévio, via sala de aula invertida, que estimula a participação dos alunos, é muito importante para o próprio docente que, além de se sentir estimulado no momento de lecionar, poderá conhecer 
as dificuldades da turma e dos alunos por meio dos assuntos debatidos, além de poder escolher os tópicos a serem aprofundados, de maior interesse ou dificuldade do coletivo.

Considerando que o conhecimento não depende somente de um fator, mas da construção de um todo, o uso da sala de aula invertida propicia numerosos benefícios quando se é aplicada e praticada adequadamente. A música pode contribuir de forma transdisciplinar com essa construção, notadamente porque estimula habilidades que não seriam desenvolvidas a partir da metodologia exclusivamente instrutivista de ensino, motivando o aluno a aproximar a teoria da prática, associando o conteúdo ao seu cotidiano e fazendo com que o modelo online de ensino tenha um funcionamento efetivo.

Nota-se que recentemente o ensino do Direito no Brasil tem passado por mudanças, decorrentes não apenas da evolução social, mas também de comandos normativos específicos, que determinam a necessidade de formação integral, inovadora, inter, multi e transdisciplinar, com o uso de metodologias construtivistas e construcionistas, por meio de métodos que valorizem o ativismo discente.

Assim, nada impede que a música também seja usada no ensino do Direito, de forma inovadora e transdisciplinar, associada à sala de aula invertida, como auxiliar na compreensão do Direito ao explicitar fatos, provar realidades e persuadir por meio da emoção que ela pode transmitir.

Por fim, resta demonstrado com esta pesquisa que ao se associar a música à sala de aula invertida, pode-se obter uma maior aproximação, interação e participação entre os alunos do curso de Direito que participam de aulas virtuais neste momento de pandemia, e que referidas aulas podem ser muito mais atrativas, interativas e engajadoras fazendo uso de tais métodos.

\section{REFERÊNCIAS}

ALVES, Lucineia. Educação a distância: conceitos e história no Brasil e no mundo. Revista Brasileira de Aprendizagem Aberta e a Distância, Rio de Janeiro, v.10, 2011.

BERGMANN, Jonathan; SAMS, Aaron. Sala de aula invertida: uma metodologia ativa de aprendizagem. 1. ed. Rio de Janeiro: LTC, 2016. 
BRASIL. Decreto-Lei n ${ }^{\circ}$ 2.848, de 7 de dezembro de 1940. Institui o Código Penal. Disponível em http://www.planalto.gov.br/ccivil_03/decreto-lei/del2848compilado.htm. Acesso em 03 ago. 2020.

BRASIL. Lei ${ }^{\circ}$ 7.716, de 05 de janeiro de 1989. Define os crimes resultantes de preconceito de raça ou de cor. Disponível em http://www.planalto.gov.br/ccivil_03/leis/17716.htm. Acesso em 14 ago. 2020.

BRASIL. Lei $\mathrm{n}^{\circ}$ 9.394, de 20 de dezembro de 1996. Estabelece as diretrizes e bases da educação nacional. Disponível em http://www.planalto.gov.br/ccivil_03/leis/19394.htm. Acesso em 14 ago. 2020.

FAKHOURY FILHO, Tamer; GABRICH, Frederico de Andrade. Pensando o Ensino Jurídico por meio das Práticas de Storytelling: O Exemplo do Júri. Revista de Pesquisa e Educação Jurídica, v. 2, n. 1, p. 110-132, 2016.

FERFEBAUM, Marina; KLAFKE, Guilherme. Ensino jurídico na quarentena: o tsunami do ensino a distância. Disponível em: http://genjuridico.com.br/2020/06/16/ensino-juridico-naquarentena/. Acesso em: 08 ago. 2020.

FREITAS, Raquel Aparecida Marra da Madeira. Ensino por problemas: uma abordagem para o desenvolvimento do aluno. Educação e Pesquisa, v. 38, n. 2, p. 403- 418, 2012.

FOREQUE, Flavia. MEC decide limitar expansão de cursos de direito em todo o país. Folha de S. Paulo, 2013. Disponível em:

https://www1.folha.uol.com.br/paywall/login.shtml?https://www1.folha.uol.com.br/edu cacao/2013/02/1234866-mec-decide-limitar-expansao-de-cursos-de-direito-em-todopais.shtml. Acesso em: 18 de ago. 2020.

GABRICH, Frederico de Andrade. Transdisciplinaridade no ensino jurídico. In: XXII ENCONTRO NACIONAL DO CONPEDI - CURITIBA, Curitiba, PR: 2013, GT: DIREITO, EDUCAÇÃO, ENSINO E METODOLOGIA JURÍDICOS. Disponível em: http://www.publicadireito.com.br/artigos/?cod=57db7d68d5335b52. Acesso em: 10 ago. 2020.

GABRICH, Frederico de Andrade. Transdisciplinaridade no ensino jurídico. Disponível em: http://www.publicadireito.com.br/artigos/?cod=57db7d68d5335b52. Acesso em: 12 ago. 2020.

GABRICH, Frederico de Andrade e TAVARES, Roselaine Andrade. Aplicação da música ao ensino do Direito. Revista de Pesquisa e Educação Jurídica. v. 6, n. 1, p. 42-61. jan./jun. 2020. Disponível em https://indexlaw.org/index.php/rpej/article/view/6519/pdf. Acesso em 31 ago. 2020. 
GRAU, Eros Roberto. A música e o Direito. Jornal O Globo, Rio de Janeiro, 13 de maio de 2014. Opinião, pág. 15. Disponível em http://www.stf.jus.br/arquivo/biblioteca/PastasMinistros/ErosGrau/ArtigosJornais/1001188.pd f. Acesso em 18 ago. 2020.

LOPES, Mônica Sete. Uma metáfora: música e direito. São Paulo, LTr, 2006.

LOPES, Mônica Sette. Direito e Música. Belo Horizonte: 2012. Rede Minas de Televisão. Programa Opinião Minas: 09 de nov. 2012. Disponível em https://www.youtube.com/watch?v=gGbkyziXSdE. Acesso em 14 ago. 2020.

MARTINES, Fernando. Primeira fase do Exame de Ordem tem recorde de candidatos reprovados. Consultor Jurídico. 2017. Disponível em: https://www.conjur.com.br/2017- set01/primeira-fase-exame-ordem-recorde-reprovações. Acesso em: 15 jul. 2020.

MORAN, J. Metodologias ativas para uma aprendizagem mais profunda. Educatrix. Dossiê̂ currículo. Ano 7, n. 12. São Paulo: Moderna, 2017. Disponível em:

http://www2.eca.usp.br/moran/wp-content/uploads/2013/12/metodologias_moran1.pdf.

Acesso em: 17 de jul. 2020.

MOURA, Taísa Ilana Maia; TASSIGNY, Mônica Mota; SILVA Thomaz Edson Veloso. O uso da tecnologia no ensino jurídico: o método do ensino híbrido no curso de direito. Revista Univap. São José dos Campos, São Paulo, Brasil. Vol. 24, n. 45, Edição Especial, 2018.

NIEMANN, Flávia de Andrade; BRANDOLI, Fernanda Maria. "Jean Piaget: um aporte teórico para o construtivismo e suas contribuições para o processo de ensino e aprendizagem da Língua Portuguesa e da Matemática. Disponível em:

http://www.ucs.br/etc/conferencias/index.php/anpedsul/9anpedsul/paper/viewFile/770/7 1 .

Acesso em: 15 jul.2020

MINISTÉRIO DA EDUCAÇÃO (Brasil). Resolução nº 5, de 17 de dezembro de 2018. Institui as Diretrizes Curriculares Nacionais do Curso de Graduação em Direito e dá outras providências. Diário Oficial da União, Brasília, 18 de dezembro de 2018, Seção 1, p. 122. Disponível em

http://portal.mec.gov.br/index.php?option=com_docman\&view=download\&alias=104111rces005-18\&category_slug=dezembro-2018-pdf\&Itemid=30192. Acesso em 02 ago. 2020.

RIGHETTI, Moacir Spadoto. O ensino jurídico e a função social da universidade. Trabalho publicado nos Anais do XVII Congresso Nacional do CONPEDI, realizado em Brasília - DF nos dias 20, 21 e 22 de novembro de 2008. 
RIOS, Mara Dutra Ramos. Sala de aula invertida: uma abordagem pedagógica no ensino superior no Brasil. Dissertação defendida no Programa de Pós-Graduação em Tecnologias, Comunicação e Educação, UFU, 2017. Disponível em:

https://drive.google.com/file/d/1 toxM3e3uwKpBPSTeXnsVqFG0eeZfkbwn/view. Acesso em 25 jun. 2020.

SILVA, Artenira da Silva e; SERRA, Maiane Cibele de Mesquita. Juristas ou técnicos legalistas? Reflexões sobre o ensino jurídico no brasil. Revista Quaestio Iuris, v. 10, n. 4, p. 2616-2636, 2017. Disponível em: https://www.e-

publicacoes.uerj.br/index.php/quaestioiuris/article/view/28197/21901. Acesso em: 20 jul. 2020.

TOMELIN, Karina Nones; TOMELIN Janes Fidélis. "Web Invertida": experiências inovadoras de metodologias de ensino ativas na Educação a Distância. São Paulo, 2015. Disponível em: http://www.abed.org.br/congresso2015/anais/pdf/BD_85.pdf. Acesso em: 21 de junho de 2020.

WERNECK, Hamilton. Como ensinar bem e avaliar melhor. Petrópolis: Vozes, 2012. 